\title{
THE ANALYSIS OF BURNISHING PROCESS INFLUENCE ON DISC BRAKE FRICTION CHARACTERISTICS AND ITS INFLUENCE ON VEHICLE SAFETY - BY INERTIA BRAKE DYNAMOMETER TESTING
}

The article describes the influence of the burnishing process on the disc brake friction characteristics. It shows the importance of brake burnish and how unburnished brake can affect vehicle safety. It shows the brake dynamometer test results obtained on six different brake pads compounds, their detailed analysis and comparison.

\section{INTRODUCTION}

During the vehicle life some of the components are getting worn out and require to be replaced. Most of them like for instance suspension, steering or exhaust system parts are immediately ready to use and fully functional after the installation but some of them need a proper preparation before they will achieve their full functionality. This kind of vehicle components are the friction brake system parts: brake discs, brake drums, brake pads, brake shoes and brake linings. When brake friction parts are newly assembled on a vehicle their contact surface is very low so they require to be properly burnished. Newly assembled brake friction components are referred to as "green brake", a brake that have not been run-in yet. Because brand new brake discs and brake pads have rather low finishing machining quality their friction area surfaces are rough, rugged and irregular which causes their working surface to be very low. That affects the brakes friction coefficient values to also be lover in comparison with burnished brake, working area of which is much larger and the contact surfaces are smother.

Many vehicle users do not even realise that green brakes are less effective than burnished brakes and they also do not know that there is a need to burnish new brake components. Vehicle owners do not know that green brake might cause a potentially dangerous road situation due to its lover friction coefficient values. Especially immediately after installing new brake friction components when the diver might not have a feeling that the brake performance is lowered and during a potentially dangerous road situation that will require extensive braking, he might find out that the brake pedal input that used to be enough to stop the vehicle is not enough this time.

On the other hand inappropriate usage of green brakes might even cause damage to the brake components or even destruction. Intensive braking while the brakes are not burnished properly might cause cavities and defects on the friction surface and local excessive heat emission which in effect might cause changes in the material structure, it also might even cause the deformation of friction components which will generate vibrations. This can make the brake difficult or even impossible to use.

The purpose of this article is to show the friction characteristics of a green brake, how does the friction characteristic change during burnishing process and a comparison of a burnishing results of different aftermarket and original equipment brake pads compound conducted on a inertia brake dynamometer.

\section{THE TEST}

\subsection{The test objects}

The test was conducted on a front brake disc from a 2009' Suzuki Alto, it is a representative of " $A$ " vehicle segment, so a small city vehicle which has small empty and gross weight, the vehicle's top velocity is low and wheel dynamic radius is large so in effect the moment of inertia reduced to the axis of one wheel is low. Those conditions allow to extend the burnishing process and makes analysing the test results easier and more precise. The technical data of the tested brake vehicle is shown in table 1.

Tab. 1. Test vehicle technical specification.

\begin{tabular}{|c|c|}
\hline Vehicle Make & Suzuki \\
\hline Vehicle Model & Alto \\
\hline Vehicle Year & $2009-2015$ \\
\hline Vehicle Engine & $1.0\left[\mathrm{dm}^{3}\right]$ R3 \\
\hline Power [kW $\mid \mathrm{BHP}]$ & $50 \mid 68$ \\
\hline Torque [Nm] & 90 \\
\hline Vmax [km/ $\mathrm{h}]$ & 155 \\
\hline Empty weight [kg] & 830 \\
\hline Gross weight $[\mathrm{kg}]$ & 1250 \\
\hline Tyre dynamic rolling radius $[\mathrm{mm}]$ & 278,55 \\
\hline Front wheel moment of inertia $\left[\mathrm{kg} \cdot \mathrm{m}^{2}\right]$ & 37,5 \\
\hline
\end{tabular}

The tested vehicle is equipped with front floating type disc brake. The brake calliper has one piston and it is guided by two brake pins which are floating in guides inside the mounting bracket. The brake disc is internally ventilated, the brake pads are mounted in the bracket via fixing springs. The tested disc brake is shown on picture number 1 and technical data is shown in table number 2 .

Tab. 2. Tested disc brake technical specification.

\begin{tabular}{|c|c|}
\hline Brake type & Floating \\
\hline Number of pistons & 1 \\
\hline Piston diameter [mm] & 51 \\
\hline Brake disc type & Internally ventilated \\
\hline Brake disc diameter [mm] & 231 \\
\hline Brake disc thickness [mm] & 20 \\
\hline Brake disc effective radius [mm] & 186,5 \\
\hline Friction surface height [mm] & 44.5 \\
\hline Brake pads height [mm] & 45,4 \\
\hline Brake pads length [mm] & 108,3 \\
\hline Brake pads thickness [mm] & 15 \\
\hline
\end{tabular}




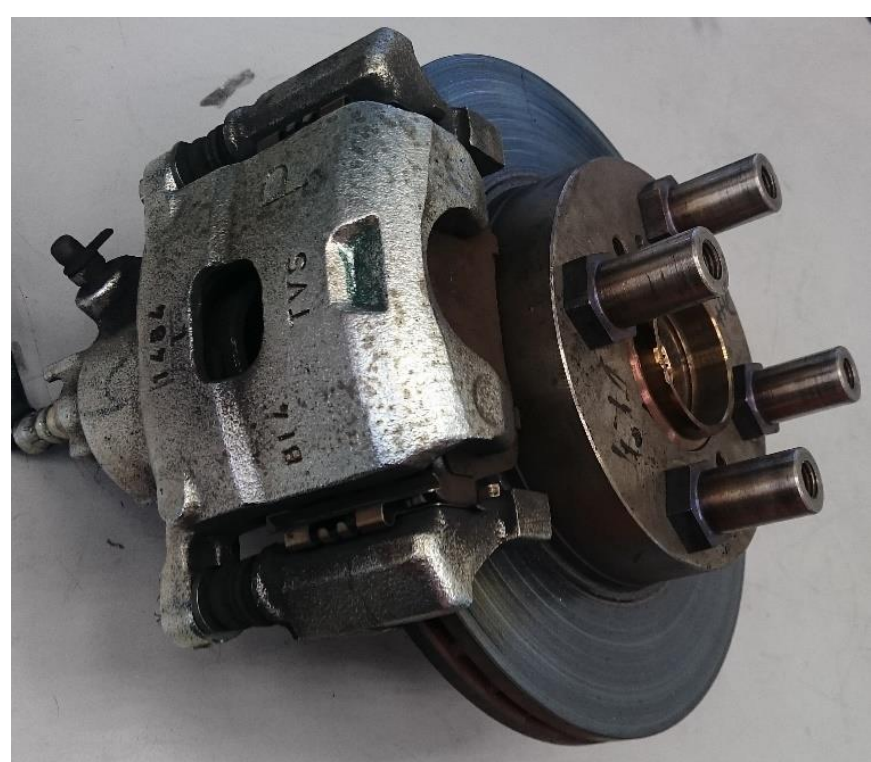

Picture. 1. The Suzuki Alto front disc brake.

The tests were conducted on six different brake pads compounds, one original equipment material, and five aftermarket from different popular manufacturers. The brake disc used was an original equipment and new for every set of brake pads. All of the tests were conducted on the same brake calliper and mounting bracket.

\subsection{The testing equipment}

In order to make sure that the test conditions were repeatable and the same as much as possible for every brake pads compound, the test had to be conducted in laboratory conditions using a test bench. The brakes were tested in BOSMAL Automotive Research and Development Institute Ltd on an Inertia Brake Dynamometer from LINK model M3000. The dynamometer is shown on picture 2.

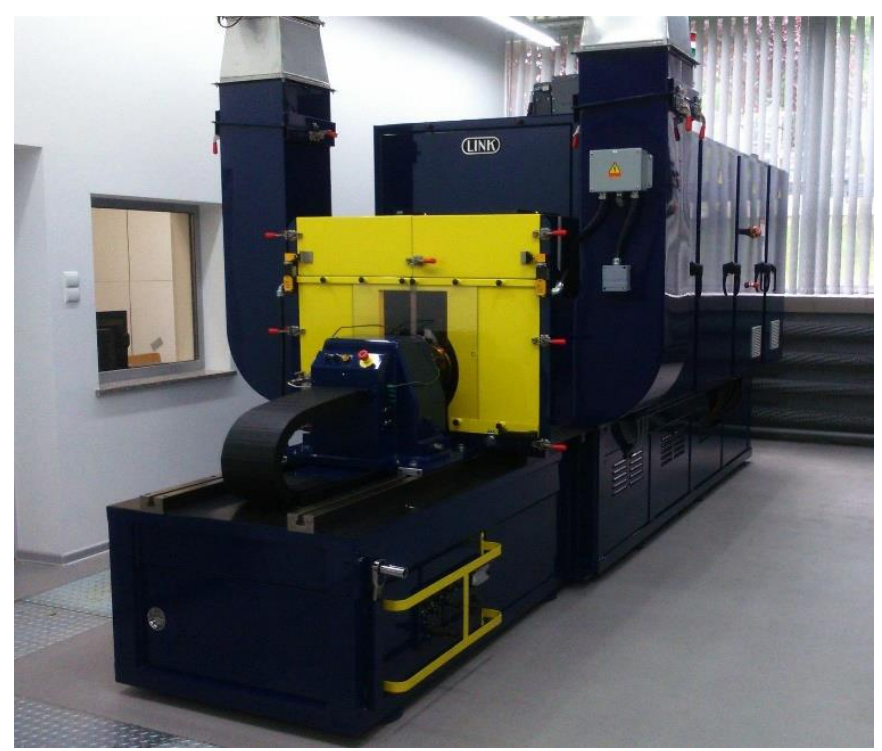

Picture. 2. The LINK M3000 Inertia Brake Dynamometer.

The dynamometer allows to test the drum and disk brake systems in real scale in range of functional tests and durability:

- friction material: brake pads and shoes

- brake drums

- solid and ventilated brake discs of each type and material.

The test bench is adapted to test:

- conventional hydraulic systems
- electro-hydraulic systems (SBC)

- electro-mechanical systems (EBM)

- hybrid brakes

Technical specification and capabilities of the Dyno are shown in table 3.

Tab. 3. The LINK M3000 specification.

\begin{tabular}{|c|c|}
\hline DC Drive Motor Power & $186 \mathrm{~kW}$ \\
\hline Rotational speed range & $0 \div 2500 \mathrm{rpm}$ \\
\hline Maximum braking torque & $5650 \mathrm{Nm}$ \\
\hline Minimum simulated moment of inertia & $5 \mathrm{kgm}^{2}$ \\
\hline Minimum mechanical moment of inertia & $42,7 \mathrm{kgm}^{2}$ \\
\hline Maximum mechanical moment of inertia & $128 \mathrm{kgm}^{2}$ \\
\hline Maximum simulated moment of inertia & $250 \mathrm{kgm}^{2}$ \\
\hline Maximum brake pressure & $20 \mathrm{MPa}$ \\
\hline Maximum pressure ramp rate & $100 \mathrm{MPa} / \mathrm{sec}$ \\
\hline
\end{tabular}

\subsection{The test procedure}

The purpose of the test was to measure the friction parameters of the tested brakes while they were burnished. The burnish procedure used was from American SAE standard - J-2522 "Dynamometer Global Brake Effectiveness" known as "AK-Master". The burnish procedure is divided into two parts, first called "Green $\mu$ characteristic section" is a set of 30 brake applications with pressure control using the same pressure level every time. This allows to check the friction coefficient of the tested brake and easy compare it to results obtained on other brake materials. The first phase test procedure is shown in table 4.

Tab. 4. Green characteristics phase test parameters.

\begin{tabular}{|c|c|}
\hline Parameter & Value \\
\hline Number of cycles & 30 \\
\hline IBT (Initial brake temperature) & $100^{\circ} \mathrm{C}$ \\
\hline FBT (Final brake temperature) & open \\
\hline Initial speed [kph] & 75 \\
\hline Final speed [kph] & 25 \\
\hline Pressure [bar] & 35 \\
\hline Cooling air speed & $0,33^{*} V \max$ \\
\hline Cooling air temperature & $25^{\circ} \mathrm{C}+/-3^{\circ} \mathrm{C}$ \\
\hline
\end{tabular}

The second burnish phase is a series of brake applications with different pressure levels in the total number of 192. Each cycle begins and ends with the same initial and final speeds and begins with the same temperature. The test parameters for the second burnish phase are shown in table number 5 .

Tab. 5. Burnish phase test parameters.

\begin{tabular}{|c|c|}
\hline Parameter & Value \\
\hline Number of cycles & 192 \\
\hline IBT (Initial brake temperature) & $100^{\circ} \mathrm{C}$ \\
\hline FBT (Final brake temperature) & open \\
\hline Initial speed [kph] & 75 \\
\hline Final speed [kph] & 25 \\
\hline Pressure [bar] & alternating: $14,35,20,24,40,26,52$ \\
\hline Number of test blocks & 6 \\
\hline Number of cycles in one block & 32 \\
\hline Cooling air speed & $0,33^{*} \mathrm{Vmax}$ \\
\hline Cooling air temperature & $25^{\circ} \mathrm{C}+/-3^{\circ} \mathrm{C}$ \\
\hline
\end{tabular}

For every test cycle the following signals were measured: braking torque, rotational speed of the brake disc, temperature of the disc and pad, the pressure in the brake system. Based on those signals and on the geometry of the brake disc and the brake calliper the friction coefficient was calculated. Also the wear of the brake pads was measured. 
The vehicles test parameter were calculated for the maximum permissible vehicle mass. The wheel dynamic radius was calculated according to manufacturer's factory data.

Each tested brake pad compound was new in the beginning of the test. The brake discs used for testing were new for every test.

\section{THE TEST RESULTS}

\subsection{Green $\boldsymbol{\mu}$ characteristics section}

The green friction coefficient characteristics section is a test with brand new brake pads and disc. Each of six test brake pads set has completed 30 cycles of first test section. After each 5 test cycles they were disassembled from the dynamometer and a contact surface was measured. The exemplary new brake pads before the test are shown on picture 3 .

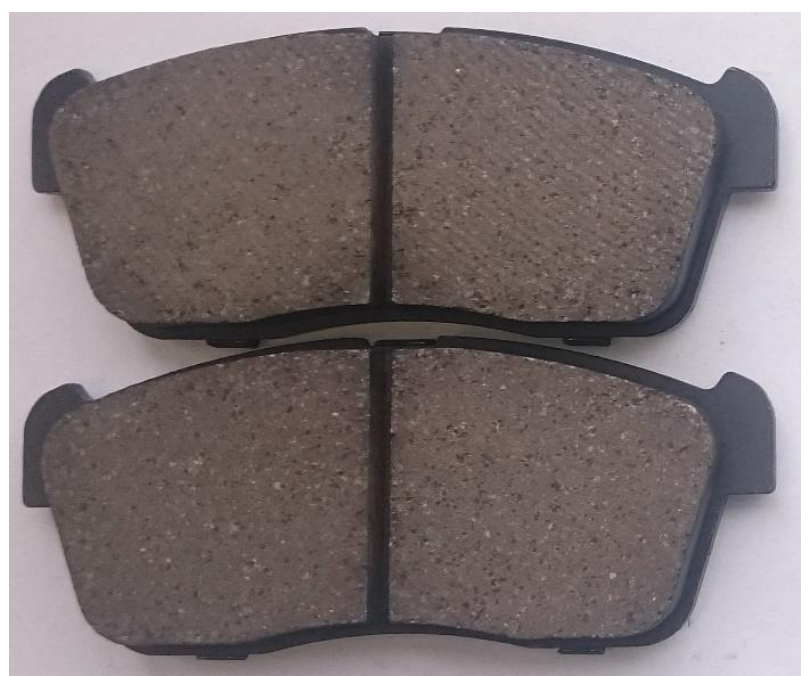

Picture. 3. The unburnished brake pads before the test.

The results of friction coefficient measurement is shown on graph number 1 and table number 6 .

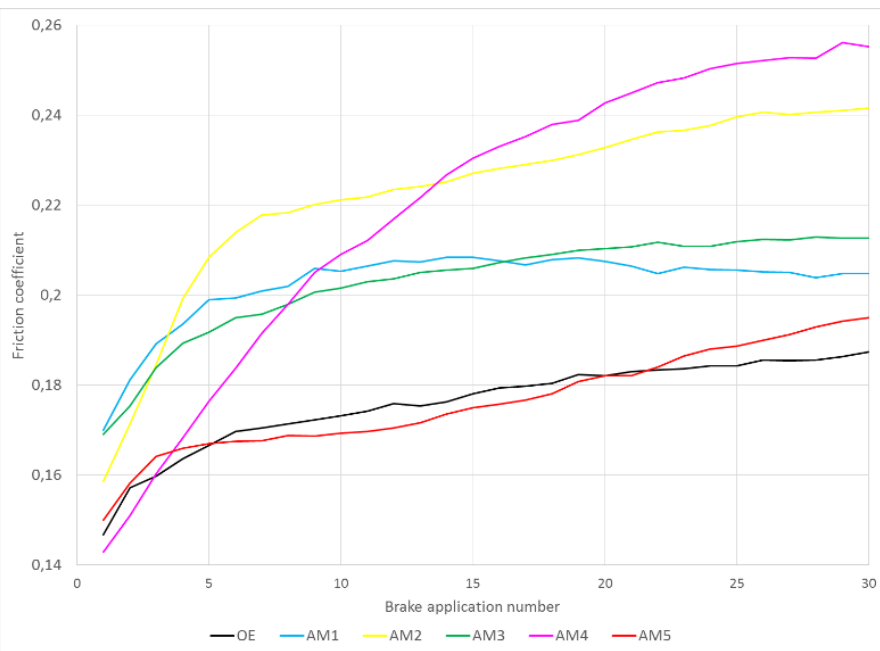

Graph. 1. The results of friction coefficient - phase one.

Tab. 6. Friction coefficient phase one results.

\begin{tabular}{|l|c|c|c|c|c|c|}
\hline Test object & OE & AM1 & AM2 & AM3 & AM4 & AM5 \\
\hline MAX $\boldsymbol{\mu}$ & 0,187 & 0,208 & 0,242 & 0,213 & 0,256 & 0,195 \\
\hline MIN $\boldsymbol{\mu}$ & 0,147 & 0,170 & 0,159 & 0,169 & 0,143 & 0,150 \\
\hline Increase & 0,041 & 0,039 & 0,083 & 0,044 & 0,113 & 0,045 \\
\hline Average $\boldsymbol{\mu}$ & 0,176 & 0,202 & 0,223 & 0,203 & 0,220 & 0,176 \\
\hline
\end{tabular}

The results of work surface increase for section one - green friction coefficient characteristics is shown on graph 2 and table 7.

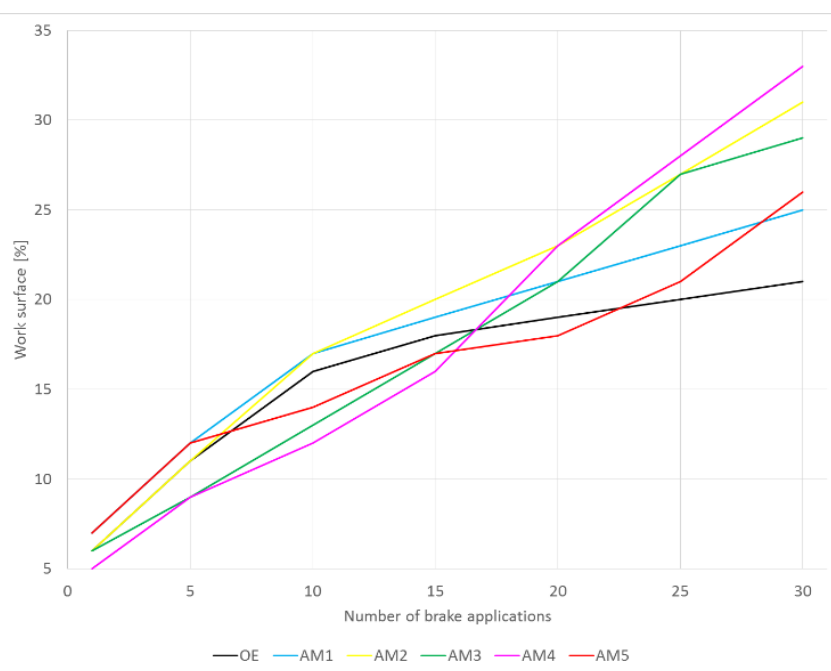

Graph. 2. The results of work surface increase - phase one.

Tab. 7. Work surface increase phase one results.

\begin{tabular}{|l|c|c|c|c|c|c|}
\hline Test object & OE & AM1 & AM2 & AM3 & AM4 & AM5 \\
\hline MIN \% & 6 & 7 & 6 & 6 & 5 & 7 \\
\hline MAX \% & 21 & 25 & 31 & 29 & 33 & 26 \\
\hline Increase \% & 15 & 18 & 25 & 23 & 28 & 19 \\
\hline
\end{tabular}

The OE and Aftermarket 5 brake pads compounds have obtained similar friction coefficient values. It begun with 0.15 and it was slowly increasing till it have reached 0.19 . The maximum achieved values were the lowest of all but they have shown a very big stability which is very important while using a vehicle. The results of work surface seem similar to the friction coefficient, in the first test phase the $O E$ work surface was increasing quicker than AM5, but at the end AM5 increase ratio was bigger.

The second similar results were obtained on AM1 and AM3 brake pads samples. In the first brake application they have achieved 0.17 and were slowly increasing until they have reached 0.21 in the final cycle. The rate of friction coefficient increase was even more moderate than the OE and AM5 have achieved. AM1 and AM3 test samples had the most stable friction coefficient of all tested brake pads and have achieved higher friction coefficient than OE and AM5 in the full test range. The work surface results are similar to those obtained with friction coefficient. For AM1 it is rising rapidly for first 10 cycles and then the rate of increase drops a bit. AM3 brake pads have nearly constant rate of work surface increase.

The AM2 test pads have begun with 0.16 friction coefficient value and it has increased rapidly till it has reached 0,22 and then the rate of increase has dropped, a clear breakdown is visible, than it continues to rise till it reaches 0,24 but the increase rate is smaller. During testing this pad the brake working surface was increasing quickly in the first 10 brake applications from $6 \%$ to $17 \%$ and then it has decreased the rate of working surface increase which is also visible in the friction coefficient graph. It has reached $32 \%$ of working surface at the end of the test.

The AM4 brake pads have achieved a very large increase in friction coefficient values, they have begun with the smallest value corresponding to 0.14 and after 30 test cycles it has reached 0.25 . The rate on increase is very high in the first part of the test and from cycle number 8 it started to decrease slightly. In comparison with other 
tested brake pads AM4 test sample achieved the smallest friction coefficient and work surface values at the first half of the test and the highest in the second half. It has achieved $33 \%$ of work surface at in the final test cycle.

\subsection{Burnish section}

The burnish section is carried out just after green friction coefficient section. Each of six test brake pads sets were subjected to 6 test parts with 32 brake applications per each. The 32 cycles are done with the same initial and final speed and alternating pressure values. After each test part the test objects were disassembled from the dynamometer and work contact surface was measured. The results of friction coefficient measurement is shown on graph number 3 and table number 8 .

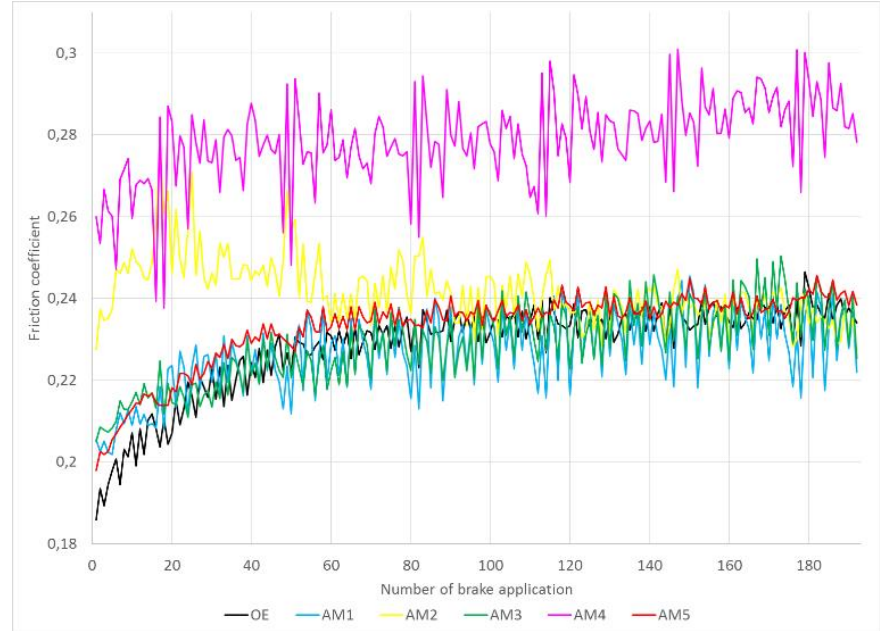

Graph. 3. The results of friction coefficient - phase two.

Tab. 8. Friction coefficient phase two results.

\begin{tabular}{|l|c|c|c|c|c|c|}
\hline Test object & OE & AM1 & AM2 & AM3 & AM4 & AM5 \\
\hline MAX $\mu$ & 0,247 & 0,245 & 0,277 & 0,250 & 0,301 & 0,246 \\
\hline MIN $\mu$ & 0,186 & 0,202 & 0,227 & 0,205 & 0,238 & 0,198 \\
\hline Increase & 0,061 & 0,044 & 0,050 & 0,045 & 0,063 & 0,048 \\
\hline Average $\mu$ & 0,228 & 0,227 & 0,242 & 0,229 & 0,279 & 0,233 \\
\hline
\end{tabular}

The results of measured work surface are shown in graph 4 and table 9.

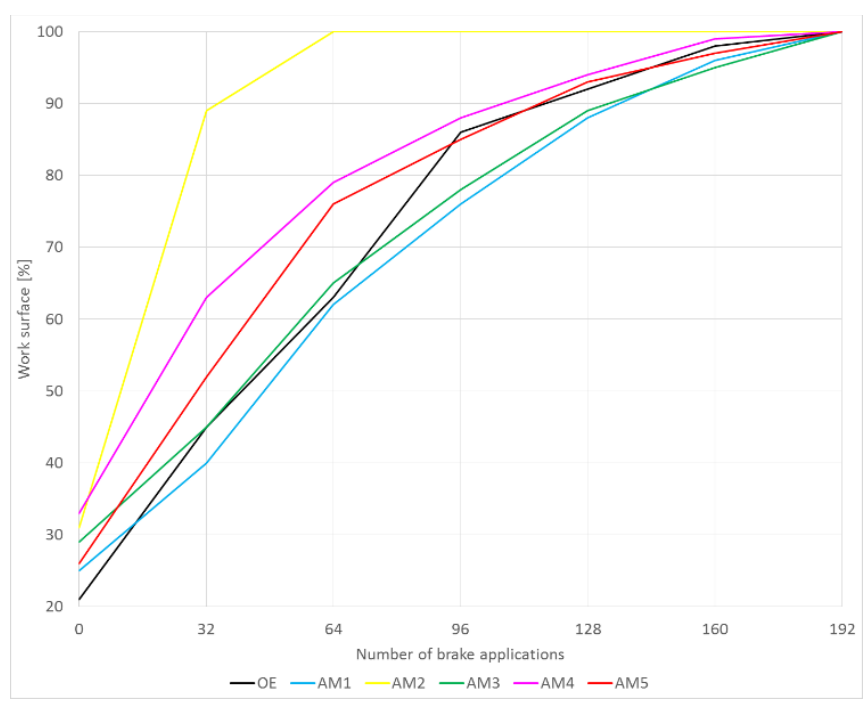

Graph. 4. The results of work surface increase - phase two.
Tab. 9. Work surface phase two results.

\begin{tabular}{|l|c|c|c|c|c|c|}
\hline Test object & OE & AM1 & AM2 & AM3 & AM4 & AM5 \\
\hline MIN \% & 21 & 25 & 31 & 29 & 33 & 26 \\
\hline MAX \% & 100 & 100 & 100 & 100 & 100 & 100 \\
\hline Increase \% & 79 & 75 & 69 & 71 & 67 & 74 \\
\hline
\end{tabular}

The OE and AM5 test samples have similar friction coefficient and work surface propagation results. The friction coefficient begins with 0.19 for AM5 and 0.2 for the OE and gradually increases in first 64 cycles up to about 0.23 for both samples, and then till the end of the test increases slightly up to about 0.24 . The friction coefficient values for those brake pads are consistent and stable and the disparity between different pressures is not high. The work surface values are increasing rapidly till 64 cycle for AM5 and till 96 cycle for OE and then till the end of the test they are similar. OE and AM5 test samples have reached $100 \%$ of work surface at the end of the test.

The AM1 and AM3 test samples are showing very similar results. They begin the test with same friction coefficient value corresponding to 0.205 and gradually increase till about cycle 64 when they reach 0.21 , from then the friction coefficient was increasing moderately till the end of the test when it has reached 0.23 . The friction coefficient values disparity in different pressure brake applications is high. The work surface values are also similar for AM1 and AM3 brake pads. They begin with about $28 \%$ and increase at the same rate till they reach $100 \%$ at the end of the test.

The AM2 test samples friction coefficient has increased rapidly in the first 32 test cycles and reached about 0.26 , but from then it started to decrease through whole test till it has reached 0.23 at the end. The disparity between the friction coefficient for brake applications in different pressures is high in the beginning of the test and is decreasing as the test progresses. The work surface has also increased very rapidly reaching nearly $90 \%$ after just 32 test cycles and achieving a full $100 \%$ just after 64 cycles. It seems that AM2 was made from a very soft friction material, which has burnished fully really quickly in the first stages of the test and then it started to glaze and loose it's friction properties.

The AM4 brake pads have achieved the highest friction coefficient values throughout the whole test and also the most stable in its friction coefficient increase rate. It begun with 0.26 and regularly increased till it has reached 0.29 at the end of the test. The friction coefficient in different pressures disparity is very high, in some cases it reaches even 0.045 . The work surface increase rate for AM4 sample is decreasing gradually throughout the whole test and the values are larger than for $\mathrm{OE}, \mathrm{AM} 1, \mathrm{AM} 3$ and $\mathrm{AM} 5$ friction materials. Finally $\mathrm{AM} 4$ pads have reached $100 \%$ of work surface after whole 192 test cycles. Exemplary brake pads set after the test are shown on picture 4 . 


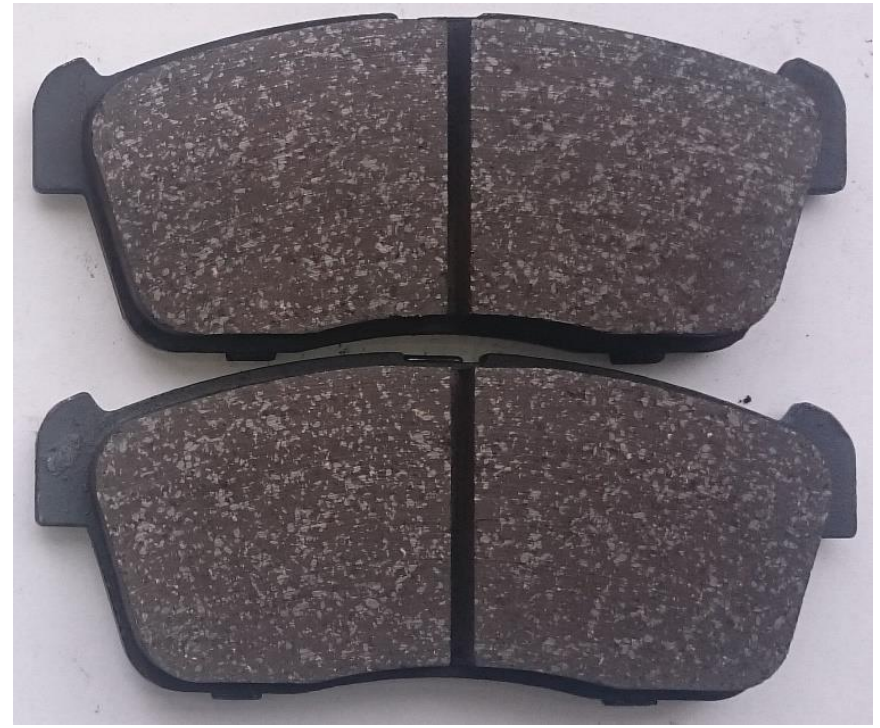

Picture. 4 The burnished brake pads - after the test.

\subsection{The results summary}

The lowest friction coefficient values are quite similar for every brake pads set tested, the lowest recorded value was for AM4 test sample -0.143 and the highest for AM1 -0.17 , the difference between all tested objects was just 0.027 . The friction coefficient disparity was bigger for the highest value -0.056 reaching the highest value for AM4 - 0.301 and lowest for AM1 -0.245 . Interesting thing was that the lowest and highest friction coefficient value was recorded for the same pad set - AM4. The difference in average friction coefficient values was 0.047 when the highest was recorded for AM4 -0.249 and lowest for the $\mathrm{OE}-0.202$. The biggest increase in friction coefficient after complete burnishing process was recorded for AM4 brake pads test set -0.158 , lowest for AM1 -0.076 , the disparity between friction coefficient for all test objects was 0.083 . The comparison of final friction coefficient results is shown in table number 10 and graph number 5 .

Tab. 10. Friction coefficient results.

\begin{tabular}{|l|c|c|c|c|c|c|}
\hline Test object & $\mathrm{OE}$ & $\mathrm{AM} 1$ & $\mathrm{AM} 2$ & $\mathrm{AM} 3$ & $\mathrm{AM} 4$ & $\mathrm{AM} 5$ \\
\hline MAX $\boldsymbol{\mu}$ & 0,247 & 0,245 & 0,277 & 0,250 & 0,301 & 0,246 \\
\hline MIN $\boldsymbol{\mu}$ & 0,147 & 0,170 & 0,159 & 0,169 & 0,143 & 0,150 \\
\hline Increase & 0,100 & 0,076 & 0,119 & 0,081 & 0,158 & 0,096 \\
\hline Average $\boldsymbol{\mu}$ & 0,202 & 0,215 & 0,232 & 0,216 & 0,249 & 0,205 \\
\hline
\end{tabular}

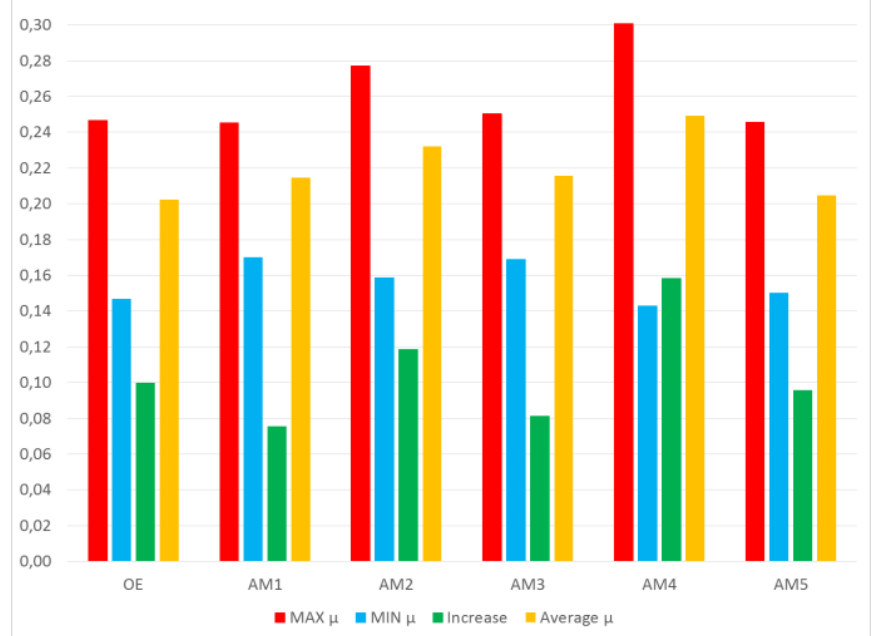

Graph. 5. Cycles required for complete burnish.
All of the tested brake pads sets have accomplished $100 \%$ of work friction surface as a result of the burnishing process. Although the number of brake applications needed to achieve a full burnished surface was different for each brake pads set. The least number of cycles required to achieve a $100 \%$ of contact was needed by the AM2 test sample which was 62 . This sample has burnished really quickly and then through the rest of the test it seemed to get glazed and polished. The highest number of test cycles needed was recorded for AM1 and AM3 test samples - 222 brake applications. Those brake pads needed nearly all of the burnish procedure in order to achieve $100 \%$ of work surface. The disparity of cycles required for full burnish between all test samples was 160 , which seems to be a lot taking into concern the whole number of cycles which was 222 . AM2 test sample achieved $1,61 \%$ pre cycle of work surface increase which was the highest of all, the smallest increase per cycle was achieved by AM1 and $\mathrm{AM} 3-0,45 \%$. The number of cycles required for full burnish is shown in table number 11 and graph number 6 .

Tab. 11. Burnish cycles results.

\begin{tabular}{|l|c|c|c|c|c|c|}
\hline Test object & OE & AM1 & AM2 & AM3 & AM4 & AM5 \\
\hline Cycles & 190 & 222 & 62 & 222 & 158 & 190 \\
\hline Increase per cycle \% & 0,53 & 0,45 & 1,61 & 0,45 & 0,63 & 0,53 \\
\hline
\end{tabular}

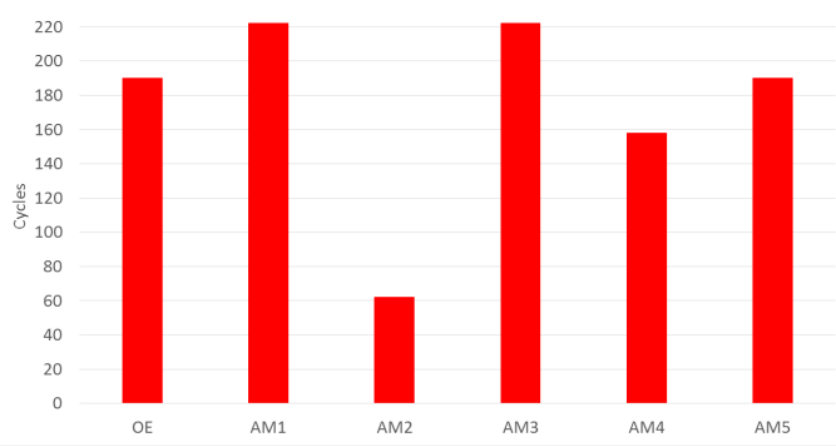

Graph. 6. Cycles required for complete burnish.

\section{SUMMARY}

The purpose of the article was to check the influence of the burnishing process of new brakes on their friction characteristics and shows the friction parameters of a brand new, unburnished brakes. The analysis was carried out using a inertia brake dynamometer which guarantees the test conditions repeatability and makes the test results possible to compare.

The test results shown that the burnishing process has a big effect on the brakes friction properties. The green brakes have a lot lower friction coefficient in comparison with fully burnished brakes. In some cases the difference in friction coefficient before and after the test is even more than $100 \%$. This shows that the burnishing process for brake friction elements is really important.

The work contact surface of the brake pads and disc when the brake is green is similar for all of the test samples and it is around $6 \%$. All of the brake pads test sets have achieved $100 \%$ work surface, but they needed different amount of brake applications in order to achieve that. The disparities are reaching $72 \%$. This means that there is a difference in the brake pads compound hardness. Soft compound brake pads are burnishing very quickly but there is a suspicion that they might wear out quicker. Harder compound brake pads are generating high friction coefficient and are burnishing quickly but it is possible that they might wear out brake disc quickly and make groves on its friction surface. 


\section{Eksploatacja i testy}

The brake burnishing process is important in vehicle safety aspect. Due to low friction coefficient unburnished brakes can cause a potentially dangerous road situation, especially immediately after switching from old brakes to new ones, when the difference in the friction coefficient is very large, the brake pedal input and brake fluid pressure has to be bigger, the vehicle driver might not expect that difference and might be surprised by the braking torque achieved by the brakes when using the same brake pedal input which previously was enough. The worrying fact is that most of service stations do not inform the vehicle owners about this risk and about the necessity to do a proper brakes burnish. Some of workshops do tell the driver to do a burnish but the procedure they are suggesting is often not correct and can make things even worse.

The brakes burnishing influence on brakes friction characteristics and their influence on vehicle safety needs more research so this will be a topic of further authors research.

\section{BIBLIOGRAPHY}

1. SAE-J2522 - "Dynamometer Global Brake Effectiveness", 2014-09

2. B. Breuer, K. H. Bill, "Brake Technology Handbook", 1nd eng. ed., Warrendale, Pennsylvania, USA, SAE, 2008.

3. R. Limpert, "Brake Design and Safety", 3rd ed., Warrendale, Pennsylvania, USA, SAE, 2011

4. K. Reif, "Brakes, Brake Control and Driver Assistance Systems", Weisbaden, Germany, Springer Vieweg, 2014

5. B. Breuer, U. Dausend, "Advanced Brake Technology", 1nd eng. ed., Warrendale, Pennsylvania, USA, SAE, 2003.
6. S. F. Scieszka, "Hamulce cierne, zagadnienia materiałowe, konstrukcyjne i tribologiczne", 1st ed., Radom, Poland, WiZPITE, 1998

7. „Hamulce w pojazdach i maszynach roboczych”, Kraków, 1988.

8. J. Jaworski, „Okładziny cierne do hamulców i sprzęgieł pojazdów mechanicznych", WKit, Warszawa, 1984.

9. Z. Osiński, „Sprzęgła i hamulce”, PWN, Warszawa, 2000.

10. Z. Szydelski, „Pojazdy samochodowe - sprzęgła, hamulce i przekładnie hydrokinetyczne", WKiŁ, Warszawa, 1981

Authors:

mgr inż. Tomasz Dąbrowski - BOSMAL Automotive Research and Development Institute, Car Assemblies Testing Department, Mechanical Testing Laboratory, Brake System Testing Laboratory.

dr inż. Dariusz Kurczyński - Kielce University of Technology, Faculty of Mechatronics and Machinery Design, Department Automotive Engineering and Transport.

dr inż. Piotr Łagowski- Kielce University of Technology, Faculty of Mechatronics and Machinery Design, Department Automotive Engineering and Transport.

mgr inż. Michał Warianek- Kielce University of Technology, Faculty of Mechatronics and Machinery Design, Department Automotive Engineering and Transport.

JEL: R41, L62 DOI: 10.24136/atest.2018.100

Data zgłoszenia: 2018.05.22 Data akceptacji: 2018.06.15 